\title{
Correction to: Emotional computing based on cross-modal fusion and edge network data incentive
}

\author{
Lei Ma ${ }^{1} \cdot$ Feng Ju ${ }^{1} \cdot$ Jing $\mathrm{Wan}^{2} \cdot$ Xiaoyan Shen ${ }^{1}$ \\ Published online: 15 February 2020 \\ (C) Springer-Verlag London Ltd., part of Springer Nature 2020
}

\section{Correction to: Pers Ubiquit Comput (2019) 23:363-372} https://doi.org/10.1007/s00779-019-01232-1

The support funding information was missed to be included in the printed version of the proof. It should have been included and should read:

Acknowledgments This work is supported by National Natural Science Foundation of China $(61534003,81371663)$ and Opening Project of State Key Laboratory of Bioelectronics in Southeast University, (Ministry of Education in China) Liberal arts and Social Sciences Foundation (17YJC890022), Natural Science Foundation of Jiangsu Province(BK20170448), and the Natural Science Foundation of the Jiangsu Higher Education Institutions of China (16KJB180019), Jiang Su Liberal arts and Social Sciences Foundation (17YJC890022). This work is also supported by the " 226 Engineering" Research Project of Nantong Government.

The online version of the original article can be found at https://doi.org/ 10.1007/s00779-019-01232-1

\footnotetext{
Xiaoyan Shen

mlmyhero@163.com

Lei Ma

malei@ntu.edu.cn

Feng Ju

2931613077@qq.com

Jing Wan

dupihedubao@163.com

1 School of Information Science and Technology, Nantong University, Nantong 226019, Jiangsu, China

2 Nantong Rail Transit Co. LTD, Nantong 226019, Jiangsu, China
} 